\title{
(6) OPEN ACCESS \\ Using venous blood gas analysis in the assessment of COPD exacerbations: a prospective cohort study
}

\author{
Tricia M McKeever, ${ }^{1}$ Glenn Hearson, ${ }^{2}$ Gemma Housley, ${ }^{3}$ Catherine Reynolds ${ }^{2}$ \\ William Kinnear, ${ }^{4}$ Tim W Harrison, ${ }^{2}$ Anne-Maree Kelly, ${ }^{5}$ Dominick E Shaw ${ }^{2,3}$
}

\begin{abstract}
- Additional material is
published online only. To view, please visit the journal online (http://dx.doi.org/10.1136/ thoraxjnl-2015-207573).
\end{abstract}

For numbered affiliations see end of article.

\section{Correspondence to} Dr Dominick E Shaw, Respiratory Research Unit, Division of Respiratory Medicine, University of Nottingham, Clinical Sciences Building, Nottingham City Hospital, Edwards Lane, Nottingham NG5 1PB, UK; dominic.shaw@nottingham.ac. uk

Received 15 July 2015 Revised 6 October 2015 Accepted 9 October 2015 Published Online First 1 December 2015

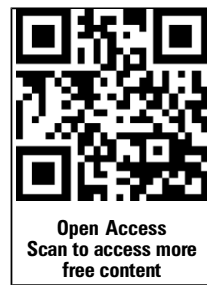

\section{SLinked}

- http://dx.doi.org/10.1136/ thoraxjnl-2015-208205

\section{CrossMark}

To cite: McKeever TM Hearson G, Housley G, et al. Thorax 2016;71:210-215.

\begin{abstract}
Introduction Identifying acute hypercapnic respiratory failure is crucial in the initial management of acute exacerbations of COPD. Guidelines recommend obtaining arterial blood samples but these are more difficult to obtain than venous. We assessed whether blood gas values derived from venous blood could replace arterial at initial assessment.
\end{abstract}

Methods Patients requiring hospital treatment for an exacerbation of COPD had paired arterial and venous samples taken. Bland-Altman analyses were performed to assess agreement between arterial and venous $\mathrm{pH}$, $\mathrm{CO}_{2}$ and $\mathrm{HCO}_{3}^{-}$. The relationship between $\mathrm{SpO}_{2}$ and $\mathrm{SaO}_{2}$ was assessed. The number of attempts and pain scores for each sample were measured.

Results 234 patients were studied. There was good agreement between arterial and venous measures of $\mathrm{pH}$ and $\mathrm{HCO}_{3}^{-}$(mean difference 0.03 and -0.04 , limits of agreement -0.05 to 0.11 and -2.90 to 2.82 , respectively), and between $\mathrm{SaO}_{2}$ and $\mathrm{SpO}_{2}$ (in patients with an $\mathrm{SpO}_{2}$ of $>80 \%$ ). Arterial sampling required more attempts and was more painful than venous (mean pain score 4 (IQR 2-5) and 1 (IQR 0-2), respectively, $\mathrm{p}<0.001)$.

Conclusions Arterial sampling is more difficult and more painful than venous sampling. There is good agreement between $\mathrm{pH}$ and $\mathrm{HCO}_{3}^{-}$values derived from venous and arterial blood, and between pulse oximetry and arterial blood gas oxygen saturations. These agreements could allow the initial assessment of COPD exacerbations to be based on venous blood gas analysis and pulse oximetry, simplifying the care pathway and improving the patient experience.

\section{INTRODUCTION}

Exacerbations of COPD are the second most common cause of emergency hospital admission in the UK, with an estimated 94000 per year. ${ }^{1}$ COPD exacerbations have a very high risk of mortality; $50 \%$ of people with a severe exacerbation will die within 4 years of an admission. ${ }^{1}$

The recognition that high flow oxygen therapy can induce hypercapnia in susceptible patients during exacerbations of $\mathrm{COPD},{ }^{2}$ and that respiratory acidosis is associated with a worse outcome ${ }^{34}$ led to a rise in arterial blood gas (ABG) sampling to measure $\mathrm{pH}, \mathrm{PaCO}_{2}, \mathrm{PaO}_{2}$ and $\mathrm{HCO}_{3}^{-}$. The current National Institute for Health and Care Excellence (NICE) COPD guidelines recommend obtaining an ABG in all patients admitted to hospital with a COPD exacerbation. ${ }^{5}$ Arterial sampling

\section{Key messages}

What is the key question?

- Can venous blood gas analysis replace arterial blood gas sampling in the initial assessment of patients with COPD exacerbations?

What is the bottom line?

- Over two-thirds of arterial blood gas samples could be replaced by the simpler and safer use of venous blood gas analysis.

\section{Why read on?}

- This paper describes agreement between arteriovenous measures for key blood gas parameters and presents a simple algorithm for the substitution of arterial blood gas sampling with venous in the initial management of patients admitted to hospital with a COPD exacerbation.

is more technically difficult and reportedly more painful $^{6}$ than venous blood gas (VBG) sampling. Administration of local anaesthetic prior to arterial sampling is recommended but seldom used, as shown in a recent survey of junior doctors where 91\% never or rarely used local anaesthesia when performing arterial puncture. ${ }^{7}$ Using less invasive measures of $\mathrm{pCO}_{2}$ and $\mathrm{SaO}_{2}$ could greatly benefit patients by both decreasing pain and streamlining the care pathway.

Recent meta-analysis data suggest good agreement between venous and arterial measurements of $\mathrm{pH}, \mathrm{HCO}_{3}^{-}$and base excess. ${ }^{8-11}$ In diabetes care arterial sampling has been replaced with venous for the monitoring of diabetic ketoacidosis. ${ }^{12}$ The use of venous samples to guide treatment in COPD exacerbations has been limited, perhaps because the relationship between arterial and venous measures of $\mathrm{CO}_{2}$ is less strong, although a $\mathrm{PvCO}_{2}$ of $>6 \mathrm{kPa}$ has been shown to have $100 \%$ (95\% CI $97 \%$ to $100 \%)$ sensitivity in identifying patients with clinically relevant hypercapnia. ${ }^{13}$

We set out to assess the relationship between arterial and venous measures of $\mathrm{PCO}_{2}, \mathrm{pH}$ and $\mathrm{HCO}_{3}^{-}$, and between arterial and pulse oximetry oxygen saturations during exacerbations of COPD, in order to establish whether VBG analysis combined with pulse oximetry could replace $A B G$ analysis in the initial assessment of COPD exacerbations. 


\section{METHODS}

Patients admitted to Nottingham University Hospitals Trust with a doctor-diagnosed exacerbation of COPD were considered for inclusion. Patients were included in the study unless they refused. If they were unable to give informed consent an approved alternative decision maker was approached. Recruited patients had an ABG and pulse oximetry performed by a junior doctor as per routine care, and a parallel paired VBG sample. Care was guided by the $\mathrm{ABG}$ results as per current clinical guidelines.

Arterial samples were collected via a heparinised needle and syringe system, and venous samples were aspirated into a separate heparinised blood gas syringe via a butterfly needle or needle. Samples were processed as soon as possible on the same ward-based blood gas analyser. Analysers were calibrated regularly in accordance with the department of medical physics standard operating procedure. Research nurses collected data on demographics, body mass index, smoking status, pain scores (visual analogue scores $0=$ no pain, $10=$ worst pain imaginable) for arterial and venous sampling and the number of attempts taken to acquire each sample.

The main outcomes were the agreements between ABG and VBG parameters, and between $\mathrm{ABG}$ and pulse oximetry measures of oxygen saturation. Secondary outcome measures included pain scores, and the number of attempts taken to obtain blood.

\section{Statistical analysis}

Agreements between venous and arterial samples for $\mathrm{CO}_{2}, \mathrm{pH}$ and $\mathrm{HCO}_{3}^{-}$, and between $\mathrm{SaO}_{2}$ and $\mathrm{SpO}_{2}$ were assessed using the Bland-Altman method. Previous studies found $40 \%$ of patients attending the Emergency Department with an exacerbation of COPD had arterial hypercarbia, and it was estimated that 200 patients would allow us to calculate the sensitivity of the venous $\mathrm{CO}_{2}$ screening threshold for detection of arterial hypercarbia with CIs of $<5 \% .^{9}{ }^{13}$ Using this sample size of 200 , our $95 \% \mathrm{CI}$ around the limits of agreement are estimated at $0.24 \times$ the $\mathrm{SD}$ of the mean difference for which $\mathrm{pH}$ is \pm 0.001 . $^{14}$

Figure 1 Bland-Altman plot for arterial and venous blood $\mathrm{pH}$ levels.
Table 1 Characteristics of study population

\begin{tabular}{lcc}
\hline & $\mathbf{n}$ & $\mathbf{N}$ \\
\hline Age (years) mean (SD) & $71.0(10.8)$ & 234 \\
Sex N (\%) & & \\
$\quad$ Male & $118(50.4)$ & \\
$\quad$ Female & $116(49.6)$ & \\
BMI (kg/m ${ }^{2}$ ) mean (SD) & $26.2(7.9)$ & 223 \\
Smoking status N (\%) & & 230 \\
$\quad$ Never & $14(6.1)$ & \\
Ex & $146(63.5)$ & \\
$\quad$ Current & $70(30.4)$ & \\
Clinical measures mean (SD) & & \\
$\quad$ Heart rate (bpm) & $98.7(20.8)$ & 234 \\
Respiratory rate & $23.6(5.9)$ & 234 \\
Systolic blood pressure (mm Hg) & $130.7(23.7)$ & 234 \\
$\quad$ Diastolic blood pressure (mm Hg) & $71.3(13.1)$ & 234 \\
\hline BMl, body mass index. & & \\
\end{tabular}

Missing data were not imputed. Receiver operating characteristic curves were used to estimate how venous $\mathrm{CO}_{2}, \mathrm{pH}, \mathrm{HCO}_{3}^{-}$ predicted arterial values and how $\mathrm{SpO}_{2}$ predicted $\mathrm{SaO}_{2}$. Area under the curve, sensitivity and specificity were calculated to predict an arterial $\mathrm{pH} \geq 7.35$ and bicarbonate $\geq 21$, and for the pulse oximetry result to predict an $\mathrm{SaO}_{2}$ of $\geq 92 \%$.

\section{RESULTS}

Over the time course of the study (from 3 February 2013 to 10 January 2014), there were 1376 admissions with a coded diagnosis of COPD exacerbation. Of these, 234 participants were recruited and had at least one paired sample of blood gases. Twelve patients declined study participation. The mean age of the population was 71 years (SD 10.8) and $50 \%$ of the population was male. Characteristics of the population are shown in table 1 .

There was good agreement between arterial and venous $\mathrm{pH}$, and between arterial and venous $\mathrm{HCO}_{3}^{-}$(figures 1 and 2 and

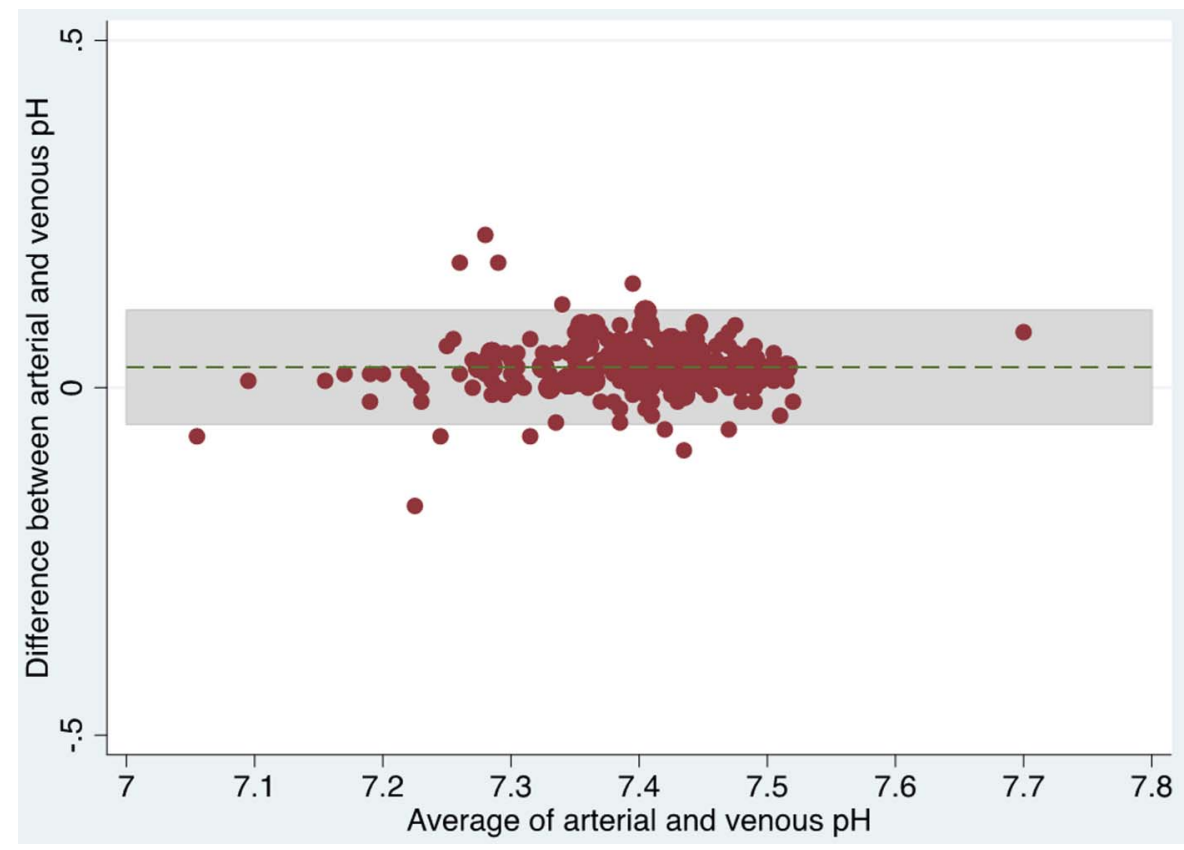




\section{Chronic obstructive pulmonary disease}

Figure 2 Bland-Altman plot for arterial and venous blood bicarbonate levels.

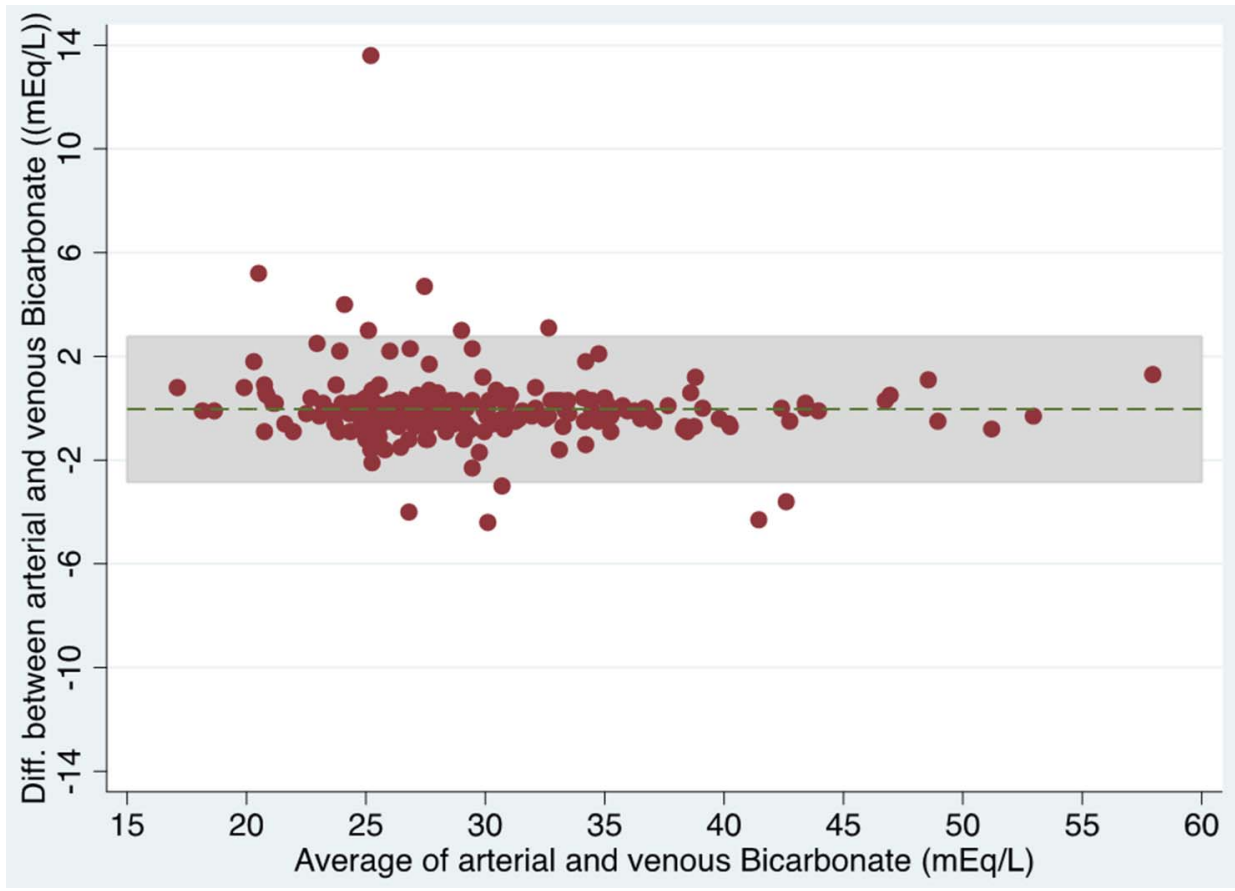

Table 2 Agreement between arterial and venous $\mathrm{pCO}_{2}, \mathrm{pH}$ and $\mathrm{HCO}_{3}^{-}$

\begin{tabular}{llllrl}
\hline & ABG (mean) (SD) & VBG (mean) (SD) & Mean difference (ABG-VBG) (95\% Cl) & 95\% limits of agreement & N \\
\hline $\mathrm{pH}$ & $7.40(0.09)$ & $7.37(0.08)$ & $0.03(0.02$ to 0.04$)$ & -0.05 to 0.11 & 234 \\
$\mathrm{HCO}_{3}^{-}(\mathrm{mEF} / \mathrm{L})$ & $29.7(6.3)$ & $29.7(6.4)$ & $-0.04(-0.22$ to 0.15$)$ & -2.90 to 2.82 & 232 \\
$\mathrm{pCO}_{2}(\mathrm{kPa})$ & $6.89(2.40)$ & $7.63(2.41)$ & $-0.75(\mathrm{Cl}-0.89$ to -0.61$)$ & -2.91 to 1.41 & 225 \\
\hline $\mathrm{ABG}$, arterial blood gas; $\mathrm{VBG}$, venous blood gas. & & &
\end{tabular}

Table 3 Agreement between $\mathrm{SaO}_{2}$ and $\mathrm{SpO}_{2}$

\begin{tabular}{clllll}
\hline & $\mathrm{SaO}_{2}$ (mean) (SD) & $\mathrm{SpO}_{2}$ (mean) (SD) & Mean difference $\left(\mathrm{SaO}_{2}-\mathrm{SpO}_{2}\right)(95 \% \mathrm{Cl})$ & $95 \%$ limits of agreement & $\mathrm{N}$ \\
\hline Oxygen percentage saturation* & $91.2(6.0)$ & $91.0(4.0)$ & $-0.17(\mathrm{Cl}-0.89$ to 0.56$)$ & -11.12 to 10.78 & 224 \\
\hline *In patients with $\mathrm{SpO}_{2} \geq 80 \%$. & & & &
\end{tabular}

Figure 3 Bland-Altman plot for arterial and venous blood $\mathrm{CO}_{2}$ levels.

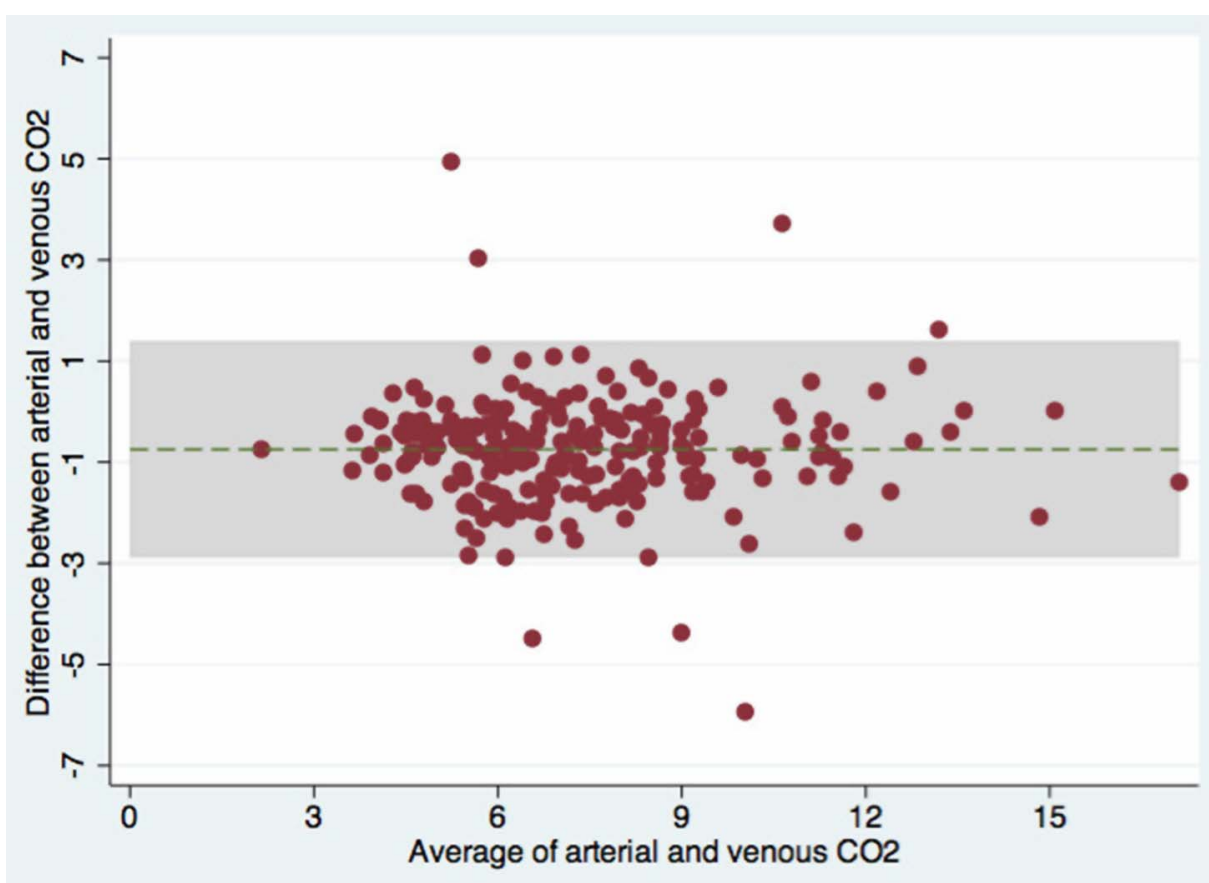

McKeever TM, et al. Thorax 2016;71:210-215. doi:10.1136/thoraxjnl-2015-207573 
Figure 4 Bland-Altman plot for $\mathrm{SaO}_{2}$ and $\mathrm{SpO}_{2}$ levels. (This graph only includes patients with a pulse oximetry value of $>80 \%$.)

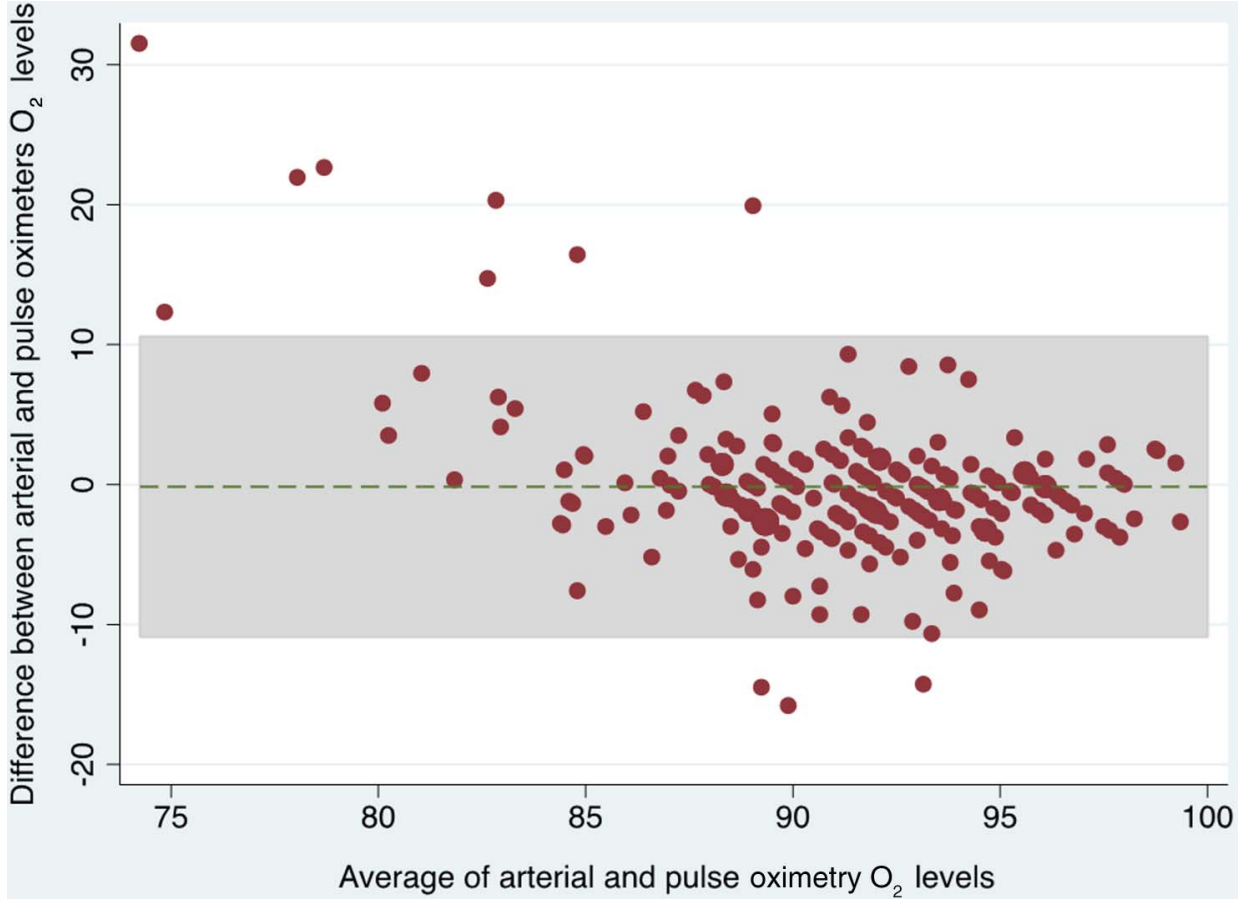

tables 2 and 3), however, the $\mathrm{CO}_{2}$ values varied significantly (figure 3). There was also a good agreement between $\mathrm{SaO}_{2}$ and $\mathrm{SpO}_{2}$ in those patients with an $\mathrm{SpO}_{2}$ of $\geq 80 \%$ (figure 4 and tables 2 and 3). These relationships were not significantly different in the 20 patients with an admission systolic blood pressure of $<100 \mathrm{~mm} \mathrm{Hg}$ (see online supplementary material).

\section{Venous blood cut points for managing acute exacerbations of COPD}

Given the relationships observed, we calculated the sensitivity and specificity of a VBG $\mathrm{pH}$ and $\mathrm{HCO}_{3}^{-}$to correctly identify an arterial $\mathrm{pH}$ of $\geq 7.35$, and an arterial $\mathrm{HCO}_{3}^{-}$of $\geq 21$, as well as an $\mathrm{SpO}_{2}$ to identify an $\mathrm{SaO}_{2}$ of $\geq 92 \%$ (table 4). A venous $\mathrm{pH}$ of 7.34, a venous $\mathrm{HCO}_{3}^{-}$of 21.45 and an $\mathrm{SpO}_{2}$ of 91.5 would have correctly classified $87 \%$ (95\% CI $82 \%$ to $91 \%), 97 \%$ (95\% CI $93 \%$ to $98 \%$ ) and $71 \%(95 \%$ CI $65 \%$ to $77 \%$ ) of patients, respectively. In terms of specificity, $96 \%$ of patients with an ABG $\mathrm{pH}$ of $\geq 7.35$ also had a VBG $\mathrm{pH}$ of $\geq 7.35$ (tables 5 and 6).

Table 4 Pain score and number of venesection attempts

\begin{tabular}{lcc}
\hline & $\mathbf{n}$ & $\mathbf{N}$ \\
\hline Pain score (median and IQR) & & \\
Arterial pain score & $4(2-5)$ & 187 \\
Venous pain score & $1(0-2)$ & 205 \\
Number of attempts (N and \%) & & \\
Arterial number of attempts & & \\
1 & $162(69.2)$ & \\
2 & $55(23.5)$ & \\
3 & $10(4.3)$ & \\
$\geq 4$ & $7(3.0)$ & \\
Venous number of attempts & & \\
1 & $211(90.2)$ & \\
2 & $18(7.7)$ & \\
$\geq 3$ & $5(2.1)$ & \\
\hline
\end{tabular}

We used current oxygen guidelines ${ }^{15}$ to calculate how many ABG samples may have been avoided if the venous cut points were used instead. Of our 234 patients, $72(31 \%)$ had a venous $\mathrm{pH}<7.35$. Of the 162 with a venous $\mathrm{pH} \geq 7.35$, only two had an arterial $\mathrm{pH}$ of $<7.35$.

Consequently, we estimate approximately two-thirds of ABGs can safely be avoided in the initial assessment of COPD exacerbations. This figure does not factor in the repeat attempts needed to obtain arterial blood. Using these data, we suggest a new algorithm for the management of COPD exacerbations based on the current guidelines (figure 5).

\section{Timing of samples}

We assessed the mean difference in time between the paired arterial and venous samples to see if a delay between samples had an effect on the relationship between ABG and VBG parameters. The mean time difference was $-4.18 \mathrm{~min}, \mathrm{SD}$ 16.92, range -58.98 to $78.64 \mathrm{~min}$ (arterial-venous). Given the range, we repeated our analysis using the 168 paired samples that were performed within $15 \mathrm{~min}$ of each other. This did not affect the relationships (see online supplementary table).

\section{Pain score}

The median pain score was significantly higher for ABG sampling as compared with VBG $(\mathrm{p}<0.001)$. In addition, there was

Table 5 Predictive performance of venous blood gas parameters

\begin{tabular}{lcccccc}
\hline & $\begin{array}{l}\text { Venous } \\
\text { blood } \\
\text { cut-off }\end{array}$ & AUC & $\begin{array}{l}\text { Sensitivity } \\
\%\end{array}$ & $\begin{array}{l}\text { Specificity } \\
\%\end{array}$ & $\begin{array}{l}\text { Correctly } \\
\text { classified } \\
\%{ }^{*}\end{array}$ & N \\
\hline $\begin{array}{l}\text { Arterial } \mathrm{pH} \\
\geq 7.35\end{array}$ & 7.34 & 0.92 & 88.9 & 95.6 & 87 & 234 \\
$\begin{array}{l}\mathrm{HCO}_{3}^{-} \\
(\mathrm{mEq} / \mathrm{L}) \geq 21\end{array}$ & 21.45 & 0.98 & 96 & 100 & 97 & 232 \\
\hline $\begin{array}{l}\text { *Correctly classified refers to percentage of patients correctly classified both above } \\
\text { and below given parameter. AUC; area under curve. }\end{array}$ &
\end{tabular}


Table 6 Predictive performance of pulse oximetry

\begin{tabular}{|c|c|c|c|c|c|c|}
\hline & $\begin{array}{l}\mathrm{SpO}_{2} \\
\text { cut-off }\end{array}$ & AUC & $\begin{array}{l}\text { Sensitivity } \\
\%\end{array}$ & $\begin{array}{l}\text { Specificity } \\
\%\end{array}$ & $\begin{array}{l}\text { Correctly } \\
\text { classified* }\end{array}$ & $\mathrm{N}$ \\
\hline $\mathrm{SaO}_{2}$ & $91.5 \%$ & 0.75 & 78 & 72 & 71 & 233 \\
\hline
\end{tabular}

a significantly greater number of attempts taken to obtain an ABG sample (69.2\% achieved at first attempt) compared with VBG, where $90.2 \%$ were obtained at the first attempt $(\mathrm{p}<0.001)$ (table 4).

\section{DISCUSSION}

Exacerbations of COPD are a major cause of morbidity and mortality worldwide, ${ }^{16}$ and our local figures reflect this. In 2010, there were 1343 admissions into Nottingham University Hospitals Trust. The management of COPD exacerbations depends upon quickly identifying acute hypercapnic respiratory failure. In this study, we set out to establish if ABG analysis obtained for the initial assessment of COPD exacerbations could be replaced by VBG analysis and pulse oximetry when assessing for acute hypercapnic respiratory failure.

We examined the agreement between ABG and VBG parameters and between $\mathrm{ABG}$ and pulse oximetry measurements of oxygen saturation in COPD exacerbations and found acceptable agreement for $\mathrm{pH}, \mathrm{HCO}_{3}^{-}$and for $\mathrm{SaO}_{2}$ at an $\mathrm{SpO}_{2}>80 \%$. We found that $96 \%$ of patients with an $\mathrm{ABG}$ pH of $<7.35$ also had a VBG $\mathrm{pH}$ of $<7.35$ and that only two patients were misclassified as having a normal venous $\mathrm{pH}$ but a low arterial $\mathrm{pH}$.

A meta-analysis of five studies examining the utility of peripheral VBG analyses in exacerbations of COPD in the emergency department found that there was agreement between arterial and venous $\mathrm{pH}$ and $\mathrm{HCO}_{3}^{-}$. 9 The weighted average difference for $\mathrm{pCO}_{2}$ was $0.79 \mathrm{kPa}(\mathrm{n}=440)$, whereas those for $\mathrm{pH}$ and $\mathrm{HCO}_{3}^{-}$were 0.028 and $1.34 \mathrm{mmol}(\mathrm{n}=239)$, respectively. The relatively weaker relationship seen between $\mathrm{SpO}_{2}$ and $\mathrm{SaO}_{2}$ at lower levels is unsurprising as commercial pulse oximeters are more accurate at higher oxygen saturations and significantly less accurate below $80 \% .{ }^{17} 18$ The proposed algorithm reflects this; any patient with an $\mathrm{SpO}_{2}$ of $<80 \%$ needs an immediate $\mathrm{ABG}$.

Our study has limitations. There was a small time gap between sample acquisition and processing, although results did not change significantly when this was factored in. We also had

Is the patient at risk of hypercapnic respiratory failure (type 2 respiratory failure)?

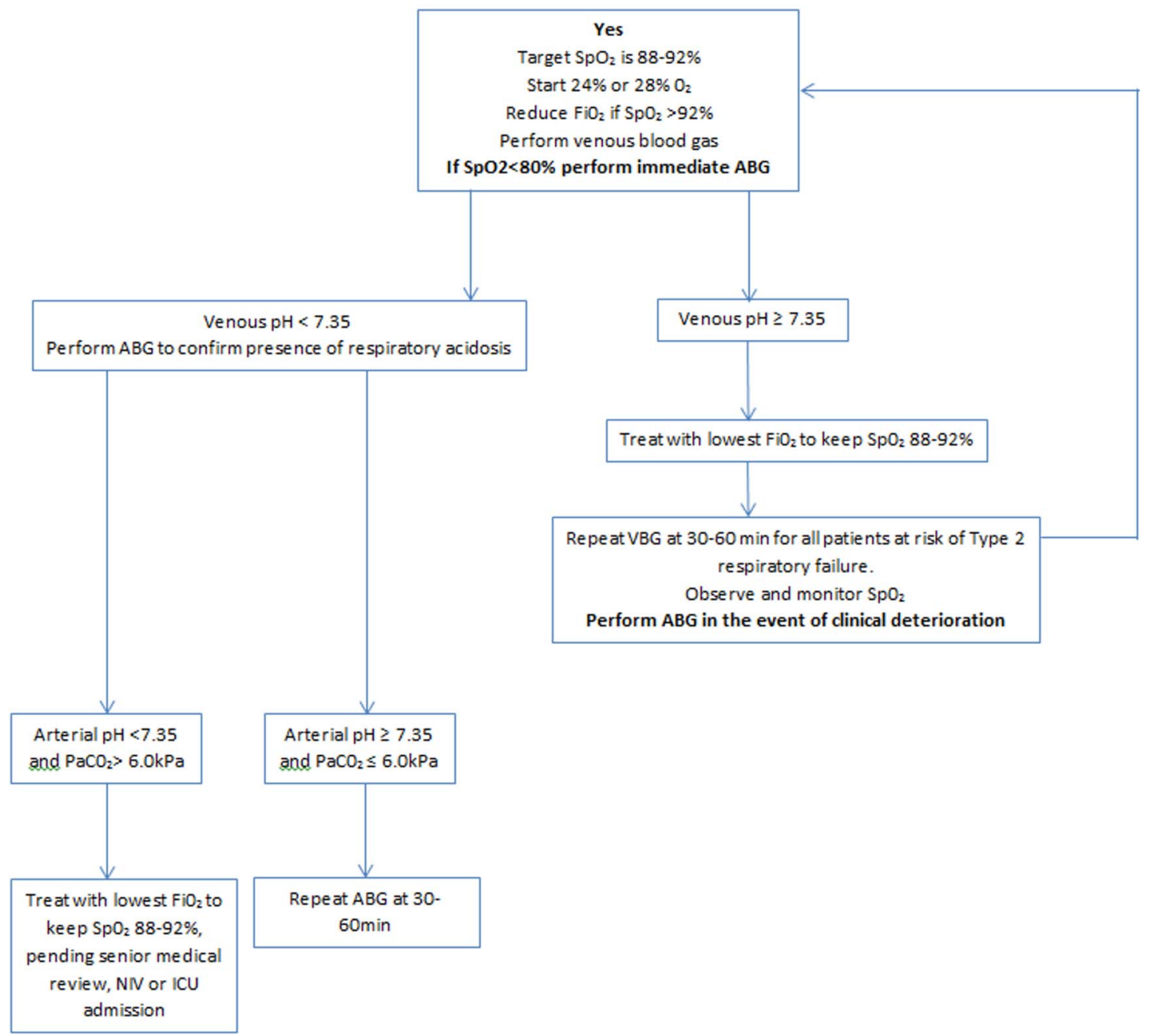

Figure 5 Suggested algorithm for blood gas analysis during COPD exacerbation (adapted from Kelly ${ }^{10}$ ). ABG, arterial blood gas; ICU, intensive care unit; NIV, non-invasive ventilation. 
a pragmatic approach to sample collection which depended upon our junior doctors and specialist nurses; consequently, it was difficult to fully exclude mixed arterial/venous stabs which may explain why the sensitivities and specificities to predict an arterial $\mathrm{pH}$ of $<7.35$ were not $100 \%$. We stress in our algorithm that if there is a risk or actual clinical deterioration an arterial analysis should be performed.

Arterial sampling was more painful than venous and required more attempts. While the pain of arterial sampling can be reduced by using local anaesthetic, it is not widely used. Although capillary sampling is used in speciality wards, widespread adoption is difficult because of the extra training, resources and time needed. As patients with exacerbations of COPD almost always have venipuncture to obtain samples for full blood count and blood chemistry analysis, VBG analysis can be performed on the same sample.

Our results suggest that the close relationship between venous and arterial acid base parameters, and between oxygen saturations obtained from pulse oximetry and arterial blood, could allow the initial assessment of acute COPD exacerbations to be based on a combined measurement of a VBG pH and $\mathrm{SpO}_{2}$. This would mean a change in practice as the current oxygen guidelines published by the British Thoracic Society ${ }^{15}$ state that any patient requiring supplemental oxygen to achieve a target $\mathrm{SpO}_{2}$ of $92 \%-94 \%$ should have an arterial blood or arteriolised capillary blood gas performed.

We suggest that arterial sampling is reserved for patients with a venous $\mathrm{pH}$ of $<7.35$. The approach of using venous blood first has obvious benefits. Only one blood draw would be required resulting in less pain and a lower risk of bruising and associated side effects. Less training would be required to initially assess acid/base status, and fewer attempts to draw blood would be needed, needing less equipment and simplifying the care pathway for COPD exacerbations. We conservatively estimate that $>66 \%$ of $\mathrm{ABG}$ attempts would be avoided and replaced by VBG sampling.

\section{CONCLUSION}

There is a good agreement between $\mathrm{pH}$ and $\mathrm{HCO}_{3}^{-}$values derived from venous and arterial blood, and between pulse oximetry and ABG oxygen saturations. These agreements could allow the initial assessment of COPD exacerbations to be based on VBG analysis and pulse oximetry rather than ABG analysis, simplifying the care pathway.

\footnotetext{
Author affiliations

'Division of Epidemiology, University of Nottingham, Nottingham, UK ${ }^{2}$ Respiratory Research Unit, Division of Respiratory Medicine, University of Nottingham, Nottingham, UK

${ }^{3}$ Medical Informatics, East Midlands Academic Health Sciences Network, Nottingham, UK

${ }^{4}$ Respiratory Medicine, Nottingham University Hospital Trust, Nottingham, UK ${ }^{5}$ Emergency Medicine, Joseph Epstein Centre for Emergency Medicine Research, Western Health, St Albans, Victoria, Australia
}

Correction notice This article has been corrected since it was published Online First. Data in the abstract and in Table 2 has been corrected. Figure 3 has been updated due to data corrections.

Twitter Follow Glenn Hearson at @NottinghamRRU

Acknowledgements The authors would like to acknowledge the expertise and help of Rachel King and Adeline Sheehan for recruiting the patients running the study. They would like to thank all the ward staff and junior doctors working in the Emergency Department, Emergency Admissions Unit, Medical High Dependency Unit and Respiratory Wards at Queens Medical Centre and Nottingham City Hospital for their help with the study, and the hospital at night nurse coordinator team. The authors also wish to acknowledge Dr Dale Gardiner for his expert blood gas input.

Contributors TMM performed the bulk of the data analyses and commented on the manuscript. GH helped with data acquisition and cleaning and commented on the manuscript. GH helped with data acquisition and follow-up data analyses and commented on the manuscript. CR and WK helped with data acquisition and commented on the manuscript. TWH helped with study design, data interpretation and commented on the manuscript. A-MK helped with study design, data interpretation and commented on the manuscript. DES had the original idea for the study, designed the study and obtained funding. He wrote the first draft.

Funding This study was funded by the National Institute for Health Research's (NIHR) research for patient benefit programme, grant number PB-PG-0211-24049. The views expressed are those of the authors and not necessarily those of the NHS, the NIHR or the Department of Health.

Competing interests None declared.

Ethics approval Nottingham Research and Ethics Committee East Midlands Nottingham 1 12/EM/0323.

Provenance and peer review Not commissioned; externally peer reviewed.

Data sharing statement Data on mortality are available; these were not included at the request of reviewer 3 but will be presented in abstract form.

Open Access This is an Open Access article distributed in accordance with the terms of the Creative Commons Attribution (CC BY 4.0) license, which permits others to distribute, remix, adapt and build upon this work, for commercial use, provided the original work is properly cited. See: http://creativecommons.org/ licenses/by/4.0/

\section{REFERENCES}

1 APPG. All party parliamentary group on respiratory health: report on enquiry into respiratory deaths. 2014.

2 Aubier M, Murciano D, Milic-Emili J, et al. Effects of the administration of $\mathrm{O}_{2}$ on ventilation and blood gases in patients with chronic obstructive pulmonary disease during acute respiratory failure. Am Rev Respir Dis 1980;122:747-54.

3 Hudson LD. Survival data in patients with acute and chronic lung disease requiring mechanical ventilation. Am Rev Respir Dis 1989;140(Pt 2):S19-24.

4 Jeffrey AA, Warren PM, Flenley DC. Acute hypercapnic respiratory failure in patients with chronic obstructive lung disease: risk factors and use of guidelines for management. Thorax 1992;47:34-40.

5 NICE. Chronic obstructive pulmonary disease: management of chronic obstructive pulmonary disease in adults in primary and secondary care. London, UK: Royal College of Physicians, 2010.

6 Dar K, Williams T, Aitken R, et al. Arterial versus capillary sampling for analysing blood gas pressures. BMJ 1995;310:24-5

7 Mangera Z, Gunasekera C, Kinley J, et al. P113 the use of local anaesthesia in improving the patient experience of arterial blood gases: students and trainers are still not getting the message. Thorax 2014;69(Suppl 2):A127.

8 Kelly AM, Kyle E, McAlpine R. Venous pCO(2) and pH can be used to screen for significant hypercarbia in emergency patients with acute respiratory disease. J Emerg Med 2002;22:15-9.

9 Lim BL, Kelly AM. A meta-analysis on the utility of peripheral venous blood gas analyses in exacerbations of chronic obstructive pulmonary disease in the emergency department. Eur J Emerg Med 2010;17:246-8.

10 Kelly AM. Review article: can venous blood gas analysis replace arterial in emergency medical care. Emerg Med Australas 2010;22:493-8.

11 Kelly AM, Klim S. Agreement between arterial and transcutaneous $\mathrm{PCO}_{2}$ in patients undergoing non-invasive ventilation. Respir Med 2011;105:226-9.

12 Kelly AM, McAlpine R, Kyle E. Venous $\mathrm{pH}$ can safely replace arterial $\mathrm{pH}$ in the initial evaluation of patients in the emergency department. Emerg Med J 2001;18:340-2.

13 Kelly AM. Can VBG analysis replace ABG analysis in emergency care? Emerg Med J 2014.

14 Bland JM, Altman DG. Statistical methods for assessing agreement between two methods of clinical measurement. Lancet 1986;327:307-10.

15 O'Driscoll BR, Howard LS, Davison AG. BTS guideline for emergency oxygen use in adult patients. Thorax 2008;63(Suppl 6):vi1-68.

16 Rabe KF, Hurd S, Anzueto A, et al. Global strategy for the diagnosis, management, and prevention of chronic obstructive pulmonary disease: GOLD executive summary. Am J Respir Crit Care Med 2007;176:532-55.

17 Jubran A. Pulse oximetry. Crit Care 1999:3:R11-7.

18 Wilson BJ, Cowan HJ, Lord JA, et al. The accuracy of pulse oximetry in emergency department patients with severe sepsis and septic shock: a retrospective cohort study. BMC Emerg Med 2010;10:9. 